\title{
EDITORIAL
}

\section{Healthcare Reform: A Risk to Pharmaceutical Innovation?}

\author{
James K. Drennen III
}

Published online: 26 June 2009

(C) International Society for Pharmaceutical Engineering 2009

While many of the pharmaceutical scientists and engineers who read Journal of Pharmaceutical Innovation are routinely focused on product development, process optimization, and countless other technical issues related to pharmaceutical research and manufacturing, each person who is employed in the pharmaceutical industry and all consumers of pharmaceutical products (in the USA and abroad) have a stake in the topic of American healthcare reform. While the debate continues regarding the best vision for a system that will offer accessible healthcare of high quality, many Americans do acknowledge a need for healthcare reform.

With common goals of improving quality, enhancing access, and reducing cost, all involved parties - government, consumers, and providers - should find an innovative approach to expand healthcare coverage to all Americans by strengthening existing public programs and expanding access to private health insurance by providing premium assistance to low-income Americans. This must be accomplished without impeding the technical innovation that is required for continued development of novel, cutting-edge, life-saving therapies. Price controls that result in inadequate payment to providers of products or services will result in less innovation, and quality will ultimately suffer.

Equally important as continued technological innovation is the need for innovations in both the health delivery system and in our approach to providing the consumer with essential information for making good decisions regarding their health insurance.

J. K. Drennen III ( $ه)$

Duquesne University,

Pittsburgh, PA, USA

e-mail: drennen@duq.edu
The Healthcare Leadership Council (HLC) believes that "uninsured Americans can have greater access to private health coverage through market reforms, tax incentives, and the use of Medicaid/CHIP dollars to help subsidize employer sponsored private insurance premiums," but that it is important to maintain a safety net for those individuals who cannot afford private health coverage even with assistance $[1,2]$. Medicaid should be available to all Americans at or below $100 \%$ of the federal poverty level, according to the HLC, and federal and state governments must maintain more effective outreach to enroll and retain eligible families and individuals.

An ideal healthcare system will provide consumer choice, a responsive market, and healthy competition among plans, improving quality and price. These characteristics are achievable only in a market economy. While the government certainly does have a role in facilitating access to healthcare for low-income Americans, this must be accomplished without obstructing private sector innovation. While some argue that healthcare reform is the key to controlling the nation's deficit, economic planning in the healthcare arena for the purpose of social justice, or any other reason, presents significant economic risk.

Addressing the US Chamber of Commerce in Washington, DC on 14 May, John C. Lechleiter, Ph.D., Chairman and CEO of Eli Lilly and Company, suggested that in addition to access, quality, and costs, the discussion on health reform also should include a focus on innovation, or the results could include "unintended side-effects." If heathcare reform does not encourage innovation, "then the important goals of expanding access, improving quality, and controlling costs will prove illusory," according to Lechleiter. 
In a 14 May 2009 Wall Street Journal opinion article, Lechleiter said that "Biomedical innovation is not incompatible with the healthcare reform goals of universal access, quality improvement, and cost control. On the contrary, without new, more effective medicines-along with new devices and diagnostic tools, and better treatments and surgical techniques - it will be impossible for larger numbers of Americans to obtain better health care at a manageable cost."'[3]

Because a significant percentage of new drug products are developed in the USA, any policy that reduces pharmaceutical innovation in the USA will have a negative impact on health outcomes for all consumers worldwide.
Technical and market innovation are the keys to a vigorous American healthcare system. Surely, we need healthcare reform, but not at the cost of innovation.

\section{References}

1. Mary R. Grealy, in May 4, 2009 letter to U.S. Senate Finance Committee regarding its May 5, 2009 Roundtable on Increasing Access to Health Care Coverage, http://www.hlc.org/html/health_reform.html. 2. "Closing the Gap," A Consensus Proposal by the Healthcare Leadership Council, http://www.hlc.org/html/health_reform.html.

3. John C. Lechleiter, "Healthcare reform and the 'Innovation Test'," http://online.wsj.com/article/SB124227053842018311.html, May 14, 2009. 